Theories \& Applications, the International Edition

Printed Version : (ISSN 2090-5262)

Online Version : (ISSN 2090-5270)

March 2014, Volume 4, No. 1 Pages $(32-39)$

\title{
Analytical Study of Some Biomechanical Variables and Their Effect on Achievement Level in the Pole Vault.
}

\section{Abdel Moneim Ibrahim Haridi}

Professor in Biological sciences and sport health department, Faculty of physical education for girls, Helwan University, Egypt.

\section{Ibrahim Ibrahim Atta}

Lecturer in Biological sciences and sport health department, Faculty of physical education for girls, Helwan University, Egypt.

\begin{abstract}
The study aims to Identify some mechanical variables and their relationship with record achievement, Researchers used the descriptive approach based on biomechanical analysis, Videography carried out in Maadi Olympic Center, Cairo, in 1st class Republic Championship in 2010 Year, Attempts analyzed and biomechanical variables identified using (video point) analysis software program which helps us to important results:

Aapproach speed is considered the most important factor affecting record achievement

Lack of dynamic and interaction between player and pole at planting phase leads to loss of part of the speed which negatively affects the energy stored in pole

Lack of interaction between player and pole during the process of pole extension from maximum flexion and lack of synchronization between pole extension and take appropriate technical positions adversely affect the benefit of overall energy stored in pole which affect achieved record.
\end{abstract}

\section{Introduction}

$\mathrm{B}$ iomechanical Analysis constitutes fundamental aspect of scientific diagnosis to describe technical performance of motor skills and measure it by some laws and mechanical foundations which crash human performance, full utilization of these laws and mechanical foundations is not realized once applied, but various variables should be measured and calculated with high degree of accuracy.

The pole vault has been in the focus of biomechanical analysis for decades with the introduction of the elastic pole effecting a change in energetic aspects
( DILLMANN and NELSON , 1968 )( 5) the event became a wide field of biomechanical interest, particularly as an example of the interaction between a biological system and an elastic mechanical implement ((9) HUBBARD ,1980; EKEVAD and LUNDBERG ， 1995( 6) ,1997(7); ARAMPATZIS et al ., 1997 (1) , 1999(3) , 2004(4) ; LINTHRONE , 2000(11); SCHADE et al ., 2000)(12)

The importance of the energy exchange between athlete and pole to improving performance is generally accepted ( e.g. HUBBARD , 1980(9) ; EKEVAN and LUNDBERG , 1995(6) , 1997( 7) ; 
ARAMPATZIS et . al ., 1997( 2) ; SCHADE et al . 2000). (12)

developed criteria , based on kinematic and kinetic data of the vaulter and the pole to study the energy transfer as the crucial aspect to explain the maximum height achieved by the centre of mass (Arampatzis et al . (1997)( 2), 2004)(4) .

A promising aspect concerning the biomechanical impact on the training process and jumping performance seems to deal with mechanical energy considerations (ARAMPATZIS et al., 1999;(3) ; SCHADE et al . 2000)(12).

The aim of the approach run is to generate kinetic energy that can be used during the interaction with the pole.

three aspects should be highlighted . first : the athlete has to perform an approach run that enables him/her to make a jump and plan action that optimises energy transfer during the take-off ( legs ) and the pole plant ( arms/trunk ) .

second : this can only be achieved by hitting the take-off point accurately ; an accuracy of $\pm 8 \mathrm{~cm}$ approximately will not influence the jump and plant action regardless the chosen jump and plant technique .

third : the athlete should achieve the highest kinetic energy possible at foot plant for take-off, having fulfilled the preconditions of the two points mentioned above .

In other words, the athlete has to achieve the maximum level of controlled velocity at the instant of touchdown for takeoff( schade et al 2006( 14 )(, 13 ).

Stability of positive accelerating in running speed level is the success key of pole vault and approach speed and level determines hand grip height could be used by player, speed defined as a mixture of step length and frequency, speed could be measured by meter, e.g. player needs speed of 7.9 $\mathrm{m} / \mathrm{sec}$. to jump to 16 feet height and 8.3 $\mathrm{m} / \mathrm{sec}$. for 17 feet and son on till last three steps. Johnston (2001)(10)

The time history of the reaction forces at the end of the ople measured in the planting box during the vault reflect the changes in the velocity of the vaulter/pole system .

This is , in fact, the result of the vaulter's action and the application of force to the pole respectively .

The absolute reaction forces in the planting box of lsinbayeva's world record and blom's winning vault. Both athletes show similar force time histories in the three components measured :

- Reaction force in horizontal direction of the runway ( $f x$ )

- Vertical reaction force ( fy )

- Reaction force perpendicular to fx ( fz ) ( schade et al 2007(

The reaction forces in horizontal direction of the runway are characterized by a clear peak at the beginning of the vault, when the pole hits the back of the planting box .

Due to his greater body mass approach velocity and pole stiffness . ( schade et al 2007( 15)

The hang phase is very marked the long swing of the leg is performed with an extended leg and the hips are brought up to or beyond shoulder hight during the rockback .

In spite of equally significant technical progress there is still potential for improvement, especially in the vertical work on the pole and the barclearance . 
( horst and Bettina (1997) (8).

Considering what listed above, Researchers who train the player who won many tournaments and broke Republic records and added new records, and won Arabic and African tournaments, she arrived to perfect technical and skill performance, but she did not reach or approach global records, although her technical performance is near to that of world champions, all this invited researchers conduct this study trying to analyze technical performance from biomechanical side as an attempt to find out deficiencies in biomechanical variables and their effect on player record.

\section{Objectives:}

1. Identify some mechanical variables and their relationship with record achievement.

\section{Methodology:}

Researchers used the descriptive approach based on biomechanical analysis resulted from Videography.

\section{Place:}

Videography carried out in Maadi Olympic Center, Cairo

\section{Time:}

Videography carried out in 1st class Republic Championship in 2010 Year

\section{Sample:}

Sample was selected intentionally , represented in Arab and Egypt champion Nasrin Imam holder of Egypt record in pole vault, Smoha Sports Club player.
Table ( 1 )

player's basic variables

\begin{tabular}{|c|c|}
\hline Date of Birth & 1986 \\
\hline Height & $167 \mathrm{~cm}$ \\
\hline Weight & $62.4 \mathrm{~kg}$. \\
\hline pole vault record & $375 \mathrm{~cm}$ \\
\hline
\end{tabular}

\section{Tools and instruments:}

- video cameras (Panasonic)

- computer

- tripod holder

- measuring pole divided into $10 \mathrm{~cm}$ (2m length ), 2 poles.

- electrical current stabilizer

- reflecting signs

- $2 \mathrm{~d}$ movement analysis program ( video point ) .

- color TV

- desk jet printer

- video capture card

\section{The Main Study :}

Main study carried as follows:

Based on previous research, scientific literature recommendation and researchers experience in the biomechanical analysis in Track and Field, videography location prepared, guidelines and scale have been set and videography field has been adjusted

Three attempts for Republic champion filmed with maximum height $(3.75 \mathrm{~m})$

Attempts have been downloaded to a laptop

Attempts divided using Ulead video studio program

Attempts analyzed and biomechanical variables identified using (video point) analysis software program 


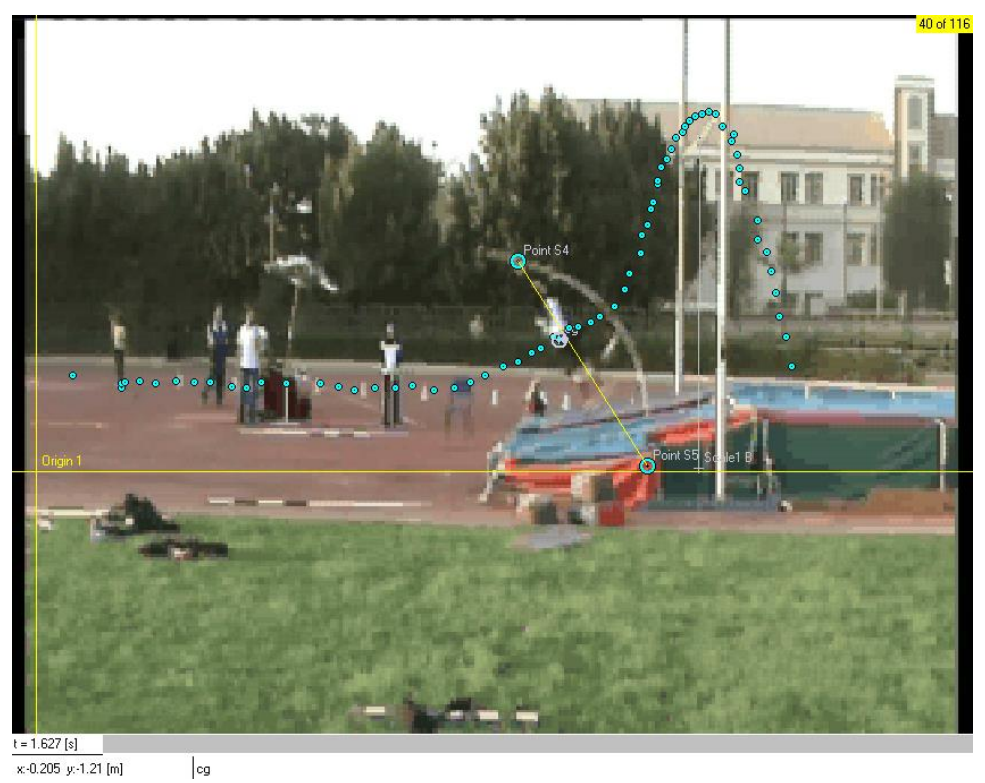

Showing Results :

Table (2)

some mechanical variables for the last three steps (at end of each step) and the moment of leaving land for pole vault

\begin{tabular}{|c|c|c|c|c|c|}
\hline & Approach Steps & fourth step & third step & pre-final step & final step \\
\hline 1 & speed $\mathbf{m} / \mathbf{s}$ & 5.32 & 7.98 & 5.13 & 5.03 \\
\hline 2 & acceleration $\mathrm{m} / \mathrm{s}^{\wedge} 2$ & 5.59 & 10.92 & 4.30 & 6.59 \\
\hline 3 & kinetic energy $(K$ E) j & 906.4 & 2038 & 842.1 & 810 \\
\hline 4 & potentionl energy (P E) mgy j & 652.1 & 630.8 & 598.7 & 694.9 \\
\hline 5 & Total energy (K E + P E) mgy $\quad($ j $)$ & 1559 & 2668 & 1441 & 1505 \\
\hline 6 & net force $n$ & 357.6 & 698.6 & 275.5 & 421.8 \\
\hline
\end{tabular}

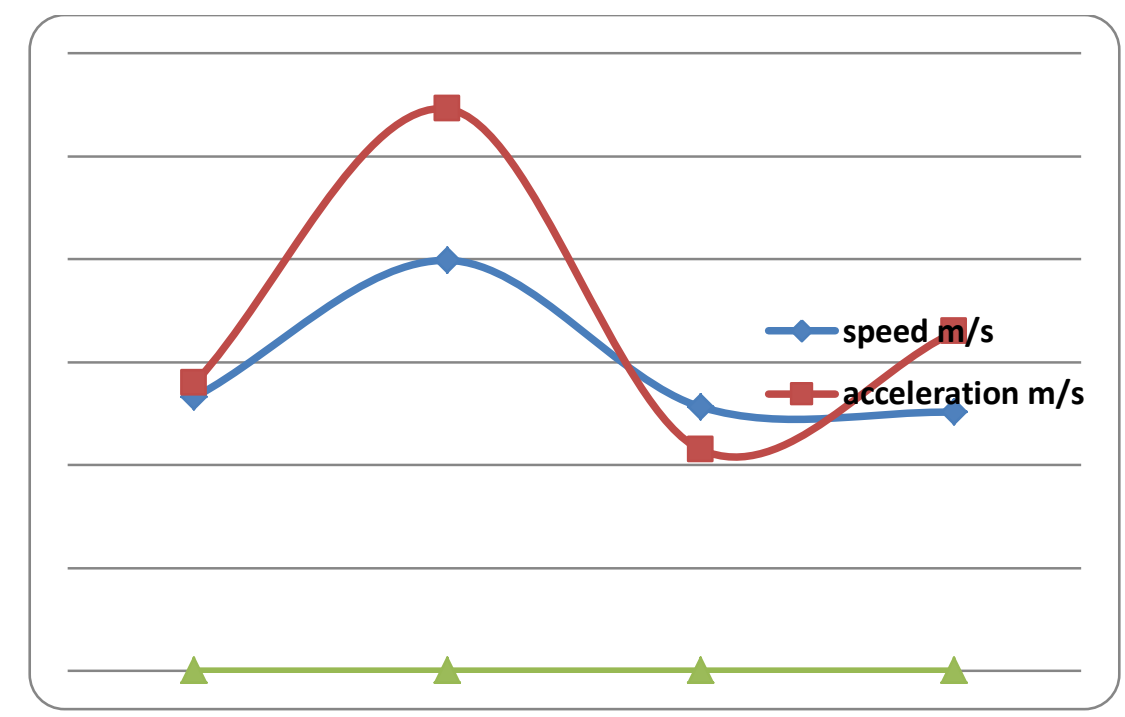




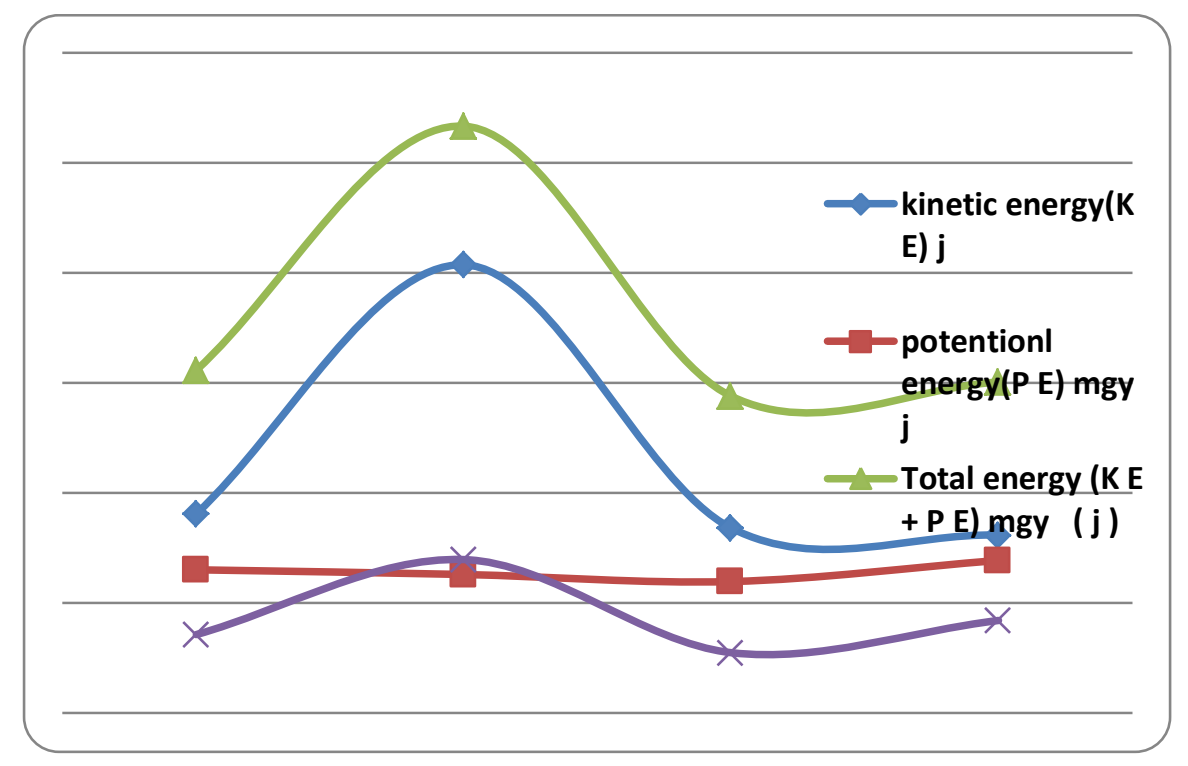

Table (3)

some mechanical variables of body center of gravity (COG)

through different heights, takeoff phase and swinging phase at the moment of maximum pole flexion

\begin{tabular}{|c|c|c|c|c|c|}
\hline & Variables & $\begin{array}{l}\text { leaving land } \\
\text { moment } \\
\text { (takeoff) } \mathrm{H1}\end{array}$ & $\begin{array}{c}\text { leaving } \\
\text { pole } \\
\text { moment } \mathrm{H2}\end{array}$ & $\begin{array}{c}\text { highest } \\
\text { center of } \\
\text { gravity H3 }\end{array}$ & $\begin{array}{l}\text { maximum pole } \\
\text { flexion }\end{array}$ \\
\hline 1 & speed m/s & 5.03 & 2.03 & 1.84 & $8.33 \mathrm{deg} / \mathrm{s}$ \\
\hline 2 & acceleration $\mathrm{m} / \mathrm{s}^{\wedge} 2$ & 6.59 & 7.81 & 22.70 & $8.83 \mathrm{deg} / \mathrm{s}^{\wedge} 2$ \\
\hline 3 & kinetic energy $(K \mathrm{~K}) \mathbf{j}$ & 810 & 131.2 & 108.4 & 311.9 \\
\hline 4 & potentionl energy(P E) mgy j & 694.9 & 2512 & 2576 & 1026 \\
\hline 5 & Total energy (K E + P E) mgy ( j ) & 1505 & 2644 & 2685 & 1338 \\
\hline 6 & net force $n$ & 421.8 & 500.1 & 1453 & 199.8 \\
\hline 7 & center of gravity ( $\mathbf{m}$ ) & 1.10 & 4.00 & 4.10 & \\
\hline 8 & angl take off (deg ) & 12.26 & & & \\
\hline 9 & $\begin{array}{l}\text { Chord length distance between } \\
\text { upper grip and planting area m }\end{array}$ & & & & 2.75 \\
\hline
\end{tabular}



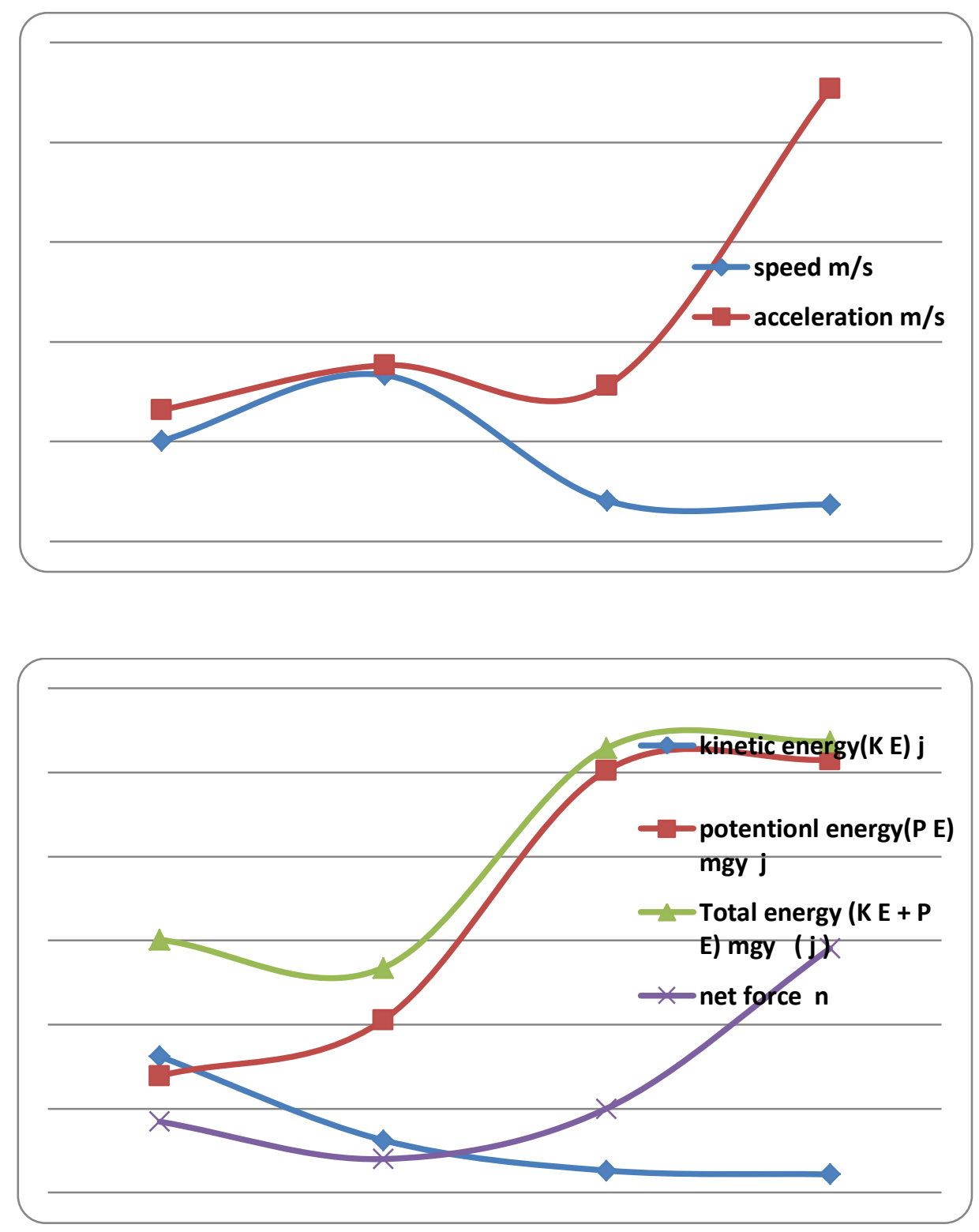

\section{Results Discussion:}

Table (2) results reveal that during the last there steps just before approaching speed rate was fluctuating where speed is at the end of third step (before the final step) was $5.32 \mathrm{~m} / \mathrm{s}$, increased during second step (before the final step) to $7.98 \mathrm{~m} / \mathrm{s}$, and then dropped in speed during pre final step to $5.13 \mathrm{~m} \mathrm{/} \mathrm{s}$, and continued to decrease during the final step (takeoff) to $5.03 \mathrm{~m} / \mathrm{s}$.

That is the opposite of what must be achieved when player entered and concentrate in takeoff and planting phase which demonstrate lack of interaction between the player and pole.

(Falk Schade et al 2006) mention that approach speed for players in Women World Championship 2005 were on continuous increasing till the final step and ranged between $7.51 \mathrm{~m} / \mathrm{s}$ s and $8.53 \mathrm{~m} / \mathrm{s}$ for the world champion, which reflected its effect on kinematic variables of pole vault (13).

For Egyptian player approaching speed negatively reflected on overall mechanical energy (KE) which were fluctuating as it declined closer to takeoff, then increased in 
takeoff to 1505 mgy j. Same effect appeared on power resultant which fluctuate declined then increased in takeoff step $421.8 \mathrm{~N}$ which indicates that player did not interact with pole in good manner.

( falk schade et ell 2007 )indicates that interaction with the pole should be in a perfect manner that will help to transfer energy to the pole without decreasing or obstructing it . ( 15 )

Table (3) shows that takeoff spade decreased to (5.03) $\mathrm{m} / \mathrm{s}$, increase of COG speed during maximum pole flexion to (8.33). Research return this to increase acceleration to enter balling and extension phase, the previous phase is power storage phase (energy) in pole and mechanical energy transmission from running and takeoff to pole (decreasing energy phase) where overall mechanical energy (1505) mgy (j) at takeoff and decreased to reach (1338 mgy (j)) at maximum pole flexion, chord length (distance between upper grip and planting place) $2.75 \mathrm{~m}$, which shows maximum pole pressure and flexion and this was result of the ideal attack angle during takeoff where (12.26 deg) and that helped to correctly enter and takeoff and pole flexion to maximum level and store energy in it.

It is clear from table (3) that player speed decreased dramatically as it was at the moment to leave the pole $2.03 \mathrm{~m} / \mathrm{s}$ and then reached $1.84 \mathrm{~m} / \mathrm{s}$ in crossing the bar and this show the end of movement and speed decreasing and acceleration increasing which helped increase the produced overall mechanical energy from the player and benefited from pole as it reached before leaving the pole to $(2644$ mgy (j)) and at crossing the bar to (2685 mgy (j)) which shows that player entered in energy increasing phase which starts from maximum pole flexion till crossing the bar.

It is clear from table (3) that the distance between COG of the player when leaving pole $\mathrm{H} 2$ and COG when crossing bar H3 was with the difference of $10 \mathrm{~cm}$ only. Player grip height was $4.05 \mathrm{~m}$ for crossing that bar with $3.75 \mathrm{~m}$ height, i.e. less than grip high while (Falk schade et ell 2007) (15) results show that grip height average of players in the 2005 Women World Championships was $4.21 \mathrm{~m}$ for crossing bar with 4.47 height, i.e. higher than bar and this make us discover deficiencies and weakness in energy translation, transport and production in energy increase phase which stored in pole; this shows lack of synchronization and coordination in motor situations performance with pole extension and which resulted in weakness and lack of benefit from pole as compared with world champions which affected player record.

\section{Conclusions}

According to research aims,
assumptions and results:

- Aapproach speed is considered the most important factor affecting record achievement

- Lack of dynamic and interaction between player and pole at planting phase leads to loss of part of the speed which negatively affects the energy stored in pole

- Lack of interaction between player and pole during the process of pole extension from maximum flexion and lack of synchronization between pole extension and take appropriate technical positions adversely affect the benefit of overall energy stored in pole which affect achieved record. 
- Trunk and arms force are important factor in achieving, as it helps the player to capture high grips and do good technical performance in which he can take advantage of energy stored in pole and transmit to player to push high to achieve a good height

\section{Recommendations:}

According to study conclusions,
researchers recommend :

- To give concern to increase approaching speed to store maximum energy in pole.

- Increase interaction between player and pole in planting phase in box so it is not affect approaching speed

- Increase swinging to increase the influence on the pole and give it more energy

- Concern to be given to exercises that help players to sense synchronization between pole extension and extension phase, crossing the bar to make the most benefit from stored energy inside the pole during its extension

\section{References}

1. Arampatzis, A.; schade, f.; bruggemann,G.-P.: pole vault in muller, H., hommel , H . ( eds. ) biomechanical research project at the vth world championships in athletics athens1997 :preliminary report . new studies in athletics (1998) 66-69 .

2. Arampatzis, A.; schade, f.; bruggemann, G.-P.:pole vault . in: Bruggemann, G. -P., Koszewski, D., muller, H. (Eds.) , biomechanical research project Athens 1997 - final report 145 - 156, 1999.

3. Arampatzis, A.; bruggemann, G.-P.: mechanical energetic processes during the giant swing exercise before dismounts and flight elements on the high bar and the uneven parallel bars . journal of biomechanics(1999) 811 - 820 .
4. Arampatzis, A.; schade, f.; bruggemann, G.-P.: Interaction between the pole and the human body and its effect on the pole vaulting performance . in : gianikellis , K.E. (Eds), scientific proceedings of the XXth international symposium on biomechanics in sports (2004) 298 - 301.

5. dillmann, c.j. ; nelson , R.C.; The mechanical energy transformations of pole vaulting with a fiberglass pole . journal of biomechanics ( 1968) 175 - 183 .

6. Ekevad , M.; lundberg, B; simulation of " smart" pole vaulting . journal of biomechanics, ( 1995) 1079-1090.

7. Ekevad, M.; lundberg, B; influence of pole length and stiffness on the energy conversion in pole vaulting - journal of biomechanics ( 1997 ) 259 - 264.

8. horst adamczewski , Bettina perlt .; runup velocities of female and male pole vaulting and some technical aspects of women's pole vault NSA ( 1997 ) (63).

9. hubbard, M.: dynamics of the pole vault . journal of biomechanics ( 1980 ) $965-976$

10. johnston ,d ,f ; six stride mark, placida , florida, 2001

11. Linthorne, N.P.: Eenergy lossin the pole vault take-off and the advantage of the flexible pole. Sports engineering ( 2000 ) $205-218$.

12. Schad , f.; Arampatzis, A.; bruggemann, G.-P.: Influence of different approaches for calculating the athlete's mechanical energy on energetic parameters in the pole vault. journal of biomechanics (2000): 1263- 1268 .

13. schade, f.; arampatzis, a. and bruggemann, g.-p.: reproducibility of energy parameters in the pole vault . Journal of biomechanics ,. ( 2006 ) 14641471

14. schade, f.; bruggemann, g.-p.; isolehto, j.; komi, p.v. and arampatzis, a. :the pole vault at the 2005 world championships in athletics: A preliminary report new studies in athletics, ( 2006 ), 57-66.

15. schade, f.; isolehto, j.; arampatzis, a.; bruggemann, g.-p. and komi, p. : biomechanical analysis of the pole vault at the 2005 iaaf world championships in athletics , ( 2007) 29-45 
